\title{
Obstetric ultrasonography: wider role for radiographers?
}

\author{
J B WITCOMBE, A RADFORD
}

\begin{abstract}
Most obstetric ultrasound scanning is carried out by radiographers, who have professional constraints that forbid them to disclose the result of any investigation to any patient or to hold themselves as professionally qualified to diagnose. A nationwide survey was carried out to explore the paramedical aspects of obstetric ultrasound services and determine how radiographers reconcile their professional constraints with the needs and expectations of patients. It was concluded that over $70 \%$ of obstetric scanning in the United Kingdom is carried out by radiographers who tell patients some results and report both numerical and interpretational data to referring clinicians.

This survey suggests that constraints on radiographers who perform obstetric ultrasonography are excessively restrictive and conflict with everyday clinical demands. The medical supervision of some obstetric ultrasound units should be improved, and partners of patients should not be encouraged to expect access to obstetric scans unless radiographers have close medical support.
\end{abstract}

\section{Introduction}

Pregnant women often look forward to their obstetric ultrasound examination. Many women expect to see images of their baby moving, some wish to share the experience with their family, and all hope to be reassured that everything looks normal. One important reason why these expectations may be unfulfilled is the professional constraints on the person who performs the ultrasound examination.

Most obstetric ultrasonography is carried out by radiographers, whose professional conduct is governed by the Disciplinary Committee of the Radiographers' Board, under the Professions Supplementary to Medicine Act of 1960. A statement this committee issued in March 1983 included the following "No registered radiographer should ... hold himself/herself out as a person who by training and experience is professionally qualified to diagnose ..." and "No registered radiographer should ... knowingly disclose to any patient or to any unauthorised person the result of any investigation ...." These dictates do not apply to other professional groups who are concerned with obstetric ultrasonography, such as nurses, midwives, medical physics technicians, or medical practitioners.

A survey of radiographers who carry out obstetric ultrasonography was undertaken to determine how these constraints affect obstetric ultrasound examinations in the United Kingdom.

\footnotetext{
Department of Radiology, Gloucestershire Royal Hospital, Gloucester GL1 3NN

J B WITCOMBE, DCH, FRCR, consultant radiologist

A RADFORD, DCR, DMU, superintendent radiographer

Correspondence to: Dr Witcombe.
}

\section{Method}

In September 1984 a questionnaire and explanatory letter were sent to the senior consultant radiologist in each of the 252 health districts in the United Kingdom. The most senior radiographer who personally carried out obstetric uitrasonography in the district was asked to complete and return the questionnaire. If no radiographers were working in obstetric ultrasonography in the district the radiologist was asked to return the form together with information about who actually performed obstetric ultrasonography.

The questionnaire asked for information on the total number of obstetric scans carried out in the district each year and the proportion performed by radiographers. There were also questions to which the radiographer replied: "usually," meaning more than $75 \%$ of the examinations, "rarely," meaning less than $25 \%$, and "often," meaning $25-75 \%$ of the examinations. Information on delivery numbers in each district was obtained from the Office of Population Censuses and Surveys, London, and the general register offices in Belfast and Edinburgh.

\section{Results}

Replies were received from 178 health districts $(70 \cdot 4 \%): 32$ radiologists said that no radiographers were active in obstetric ultrasonography in their districts, and 146 radiographers returned the completed questionnaire. The annual total number of obstetric scans (average 1.75 per live birth) and the proportion performed by radiographers were known in 140 districts. Over one and a quarter million obstetric scans are performed each year in the United Kingdom, and $74 \cdot 2 \%$ of these are carried out by radiographers. Radiographers carry out a higher proportion of obstetric scans in England and Wales $(79.9 \%)$ than in Scotland $(35.4 \%)$ or Northern Ireland (roughly $15 \%)$.

Of the radiographers who replied, $112(77 \%)$ had the diploma of medical ultrasound and $26(18 \%)$ had written permission from their employing authority agreeing to their communicating some results to patients. Real time scanners were available to all responding radiographers.

Tables I-III show the numerical results as percentages of the total answers to each question. Several radiographers mentioned alternatives to the answers in question 7 , and $15(10 \%)$ did not indicate any of the offered options in question 7 (table I). Some of the radiographers who said that they usually reported fetal abnormality (question $10 \mathrm{~d}$ ) added that they always had these findings checked by an obstetrician or a radiologist; 22 said that they allowed fathers to witness the scan at the end of the examination if no abnormality had been discovered; eight $(6 \%)$ of these replied either usually or often to question 12 (table II); and $14(10 \%)$ answered rarely or never. A few radiographers commented that fathers were allowed to witness the examination only when a doctor was present.

\section{Discussion}

Unexpected findings are common in obstetric ultrasonography: disparity between fetal size and menstrual history, fetal abnormality, or features that require a repeat examination or a medical opinion for elucidation. A medical practitioner may not be immediately available, and if problems arise a radiographer must use his or her judgment: the patient may be asked to wait and see a doctor, return for repeat scanning, return to the antenatal clinic, or see her general practitioner sooner than expected. The radiographer then has to provide some explanation. Many patients expect reassurance at the end of the examination, and understandably the commonest 
TABLE I-Radiographers and communication with mothers

\begin{tabular}{|c|c|c|c|c|}
\hline Question & $\begin{array}{l}\text { Usually } \\
(\%)\end{array}$ & $\begin{array}{c}\text { Often } \\
(\%)\end{array}$ & $\underset{(\%)}{\text { Rarely }}$ & $\begin{array}{c}\text { Never } \\
(\%)\end{array}$ \\
\hline $\begin{array}{l}\text { 1: Do you let the mother see the } \\
\text { baby moving on the screen? }\end{array}$ & 90 & 8 & 1 & 1 \\
\hline $\begin{array}{l}\text { 2: Do you explain the fetal } \\
\text { anatomy to the mother? }\end{array}$ & 71 & 19 & 8 & 2 \\
\hline $\begin{array}{l}\text { 3: If you are satisfied the } \\
\text { examination is normal do you } \\
\text { reassure the mother? }\end{array}$ & 76 & 14 & 8 & 3 \\
\hline $\begin{array}{l}\text { 4: If you diagnose twins do you } \\
\text { tell the mother? }\end{array}$ & & & & \\
\hline $\begin{array}{l}\text { 5: Do you tell the mother the } \\
\text { estimated gestational age deduced } \\
\text { from the biparietal diameter if: } \\
\text { it corresponds to the }\end{array}$ & 69 & 16 & 8 & 6 \\
\hline $\begin{array}{l}\text { menstrual history } \\
\text { it does not correspond }\end{array}$ & 69 & 13 & 7 & 10 \\
\hline to the menstrual history & 45 & 27 & 13 & 15 \\
\hline $\begin{array}{l}\text { 6: If fetal abnormality is } \\
\text { suspected do you tell the mother? }\end{array}$ & 2 & 3 & 21 & 73 \\
\hline $\begin{array}{l}\text { 7: If you suspect fetal abnormality } \\
\text { and the mother asks if the baby } \\
\text { is all right do you: }\end{array}$ & & & & \\
\hline decline to comment & 74 & 5 & 10 & 11 \\
\hline tell her about the problem & 3 & 5 & 25 & 67 \\
\hline falsely reassure her & 3 & 4 & 14 & 79 \\
\hline
\end{tabular}

TABLE II-Radiographers and doctors: reporting duties and medical supervision

\begin{tabular}{lcccc}
\hline Question & $\begin{array}{c}\text { Usually } \\
(\%)\end{array}$ & $\begin{array}{c}\text { Often } \\
(\%)\end{array}$ & $\begin{array}{c}\text { Rarely } \\
(\%)\end{array}$ & $\begin{array}{c}\text { Never } \\
(\%)\end{array}$ \\
\hline $8: \quad \begin{array}{l}\text { Is an obstetrician immediately } \\
\text { available to see the patient } \\
\text { and deal with problems? }\end{array}$ & 52 & 32 & 11 & 5 \\
9: Is a radiologist immediately \\
$\begin{array}{l}\text { available to see the patient } \\
\text { and deal with problems? }\end{array}$ & 25 & 34 & 19 & 21 \\
10: If you carry out an ultrasound \\
$\begin{array}{l}\text { scan do you personally report: } \\
\quad \text { estimated gestational age } \\
\text { multiple pregnancy }\end{array}$ & 94 & 3 & 1 & 2 \\
$\quad \begin{array}{l}\text { placental position } \\
\text { fetal abnormality }\end{array}$ & 97 & 1 & 1 & 2 \\
\hline
\end{tabular}

TABLE III-Radiographers and patients' partners

\begin{tabular}{|c|c|c|c|c|}
\hline Question & $\begin{array}{c}\text { Usually } \\
(\%)\end{array}$ & $\begin{array}{c}\text { Often } \\
(\%)\end{array}$ & $\begin{array}{c}\text { Rarely } \\
(\%)\end{array}$ & $\begin{array}{c}\text { Never } \\
(\%)\end{array}$ \\
\hline $\begin{array}{l}\text { 11: If a partner accompanies the } \\
\text { mother do you suggest he may } \\
\text { like to stay with her during } \\
\text { the examination? } \\
\text { 12: If a mother asks if her partner } \\
\text { may stay with her during the } \\
\text { examination do you agree to this? }\end{array}$ & 31 & 8 & 13 & 48 \\
\hline
\end{tabular}

question that patients ask is "Is the baby all right?" In practice, a radiographer cannot relate to a patient without giving some, albe: qualified, information.

The range of activity of radiographers is influenced by professional qualification and experience: accepted practice, and formal constraints. Of the radiographers wii responded to this survey, $77 \%$ hold the diploma of medical ultrasound, which is the only non-medical qualification in diagnostic ultrasonography and is organised by the College of Radiographers. The diploma is granted after examination by medical and radiographical examiners and assessment of a detailed record of practical training. The requirements for entry to the examination stipulate at least one year's practice in ultrasonography and experience of a minimum of 400 specified ultrasound examinations, including at least 250 obstetric examinations. About half the entrants pass the examination. Accepted practice varies from one unit to another. The results of this survey show that in most units the practice of radiographers exceeds the limits of formal constraints, and this practice has medicolegal implications for individual radiographers.

The relationship of the radiographer, not only with the pregnant patient but also with the patient's doctor and the patient's partner, has assumed more importance as the impact of ultrasonography on obstetric care has increased.

\section{RADIOGRAPHERS AND PATIENTS}

Over three quarters of a million obstetric scans are carried out in the United Kingdom each year by radiographers, who can make antenatal examinations interesting for patients by explaining the technique and showing the fetus. The interest of most mothers, however, is in their own baby, and questions on the wellbeing of the fetus often follow any demonstration. Answers to such questions are outside the remit of radiographers, but in practical terms they cannot avoid answering some of the questions without the patient either becoming anxious about undisclosed abnormalities or losing faith in the ability of the radiographer.

Table I shows that in most examinations radiographers will show the fetus to the mother (questions 1 and 2), give reassurance about the normality of the fetus (question 3), and tell the patients about multiple pregnancy (question 4). The estimated gestational age of the fetus is not only a fact that mothers wish to know but also information that will affect the organisation of antenatal care. If as a result of the ultrasound measurement it is necessary to change appointments for the antenatal clinic, $\alpha$ fetoprotein blood tests, or follow up ultrasound examinations these changes may be made most easily in the ultrasound unit. The mother, however, needs to know why the changes of appointment are necessary. Question 5 indicates that a significant proportion of radiographers tell the patient the gestational age estimated from ultrasonic measurements even when it does not correspond with the menstrual history.

When the fetus is abnormal the radiographer must first recognise the abnormality and then deal with the finding in a skilful and tactful fashion, particularly if the mother asks direct questions. In these circumstances problems are minimised when medical supervision is close. There may be a delay, however, while a doctor comes from another department or a repeat appointment may be given for the patient to be examined ultrasonically by a doctor. Most radiographers may be expected to prevaricate with phrases such as "I cannot get a very good picture," and this proved a difficult aspect to explore (questions 6 and 7). Fifteen radiographers (9\%) did not answer question 7 , possibly because they always had medical support and found all the options offered in question 7 unacceptable.

Radiographers acknowledge that most information is best told to the patient by their doctor and realise that confusion and anxiety may sometimes be provoked by unnecessary comment. Many patients, however, interpret lack of communication as obstruction or worry that information is being withheld about some abnormality. Of the responding radiographers, 26 (18\%) had already acquired written authorisation from their employing authority agreeing to their exceeding their formal constraints, suggesting that the current rules are excessively restrictive. Realistic constraints rather than impractical restrictions are needed.

\section{RADIOGRAPHERS AND DOCTORS}

The closeness and quality of medical supervision of obstetric ultrasound units vary enormously. Eight radiographers (6\%) said that both radiologists and obstetricians were rarely or never available to deal with problems immediately. The status or level of ultrasound expertise of medical practitioners who deal with urgent problems was not determined in this study, but even in well supervised units most women will see only a radiographer.

Reporting the result of diagnostic imaging procedures has traditionally been the duty of radiologists. The answers to question 10 (table III) show that radiographers not only routinely report both numerical and interpretational data but surprisingly many report fetal abnormality. A few, however, qualified their answer to question $10 \mathrm{~d}$ by saying that their findings were always checked by a doctor. It is not known how often radiographers take hard copy 
images to support their findings or how often the findings are checked by a doctor with ultrasound experience. Nevertheless, clearly with the tacit agreement of medical colleagues radiographers examine patients, draw diagnostic conclusions, and report their findings to referring clinicians.

\section{RADIOGRAPHERS AND PATIENTS' PARTNERS}

Patients often wish their partners to see the antenatal scan and the Royal College of Obstetricians and Gynaecologists thinks that this should be allowed and indeed encouraged. ${ }^{\prime}$ A modern scan requires careful examination of many anatomical structures, such as the fetal heart, spine, brain, kidneys, and stomach, and several structures are accurately measured. Radiographers often find that the presence of fathers is distracting and usually leads to a longer examination and more questioning, many of the required answers being outside the remit of a radiographer. Some units have the minimum of space and no accommodation for fathers. The main problem arises, however, when fetal abnormalities or interpretational problems are discovered. The presence of a questioning father makes it difficult for the radiographer to ensure tactfully that follow up is appropriate, while imparting the minimum of factual information.

Many radiographers feel strongly that fathers should be welcomed but others are equally convinced that it is in the best interests of the mother and fetus that the partner be excluded from the antenatal scanning. This issue is emotive and provoked more spontaneous comments in this survey than any other aspect of the study.

Whatever the community and health authorities decide about providing resources to accommodate partners families should not be encouraged to expect access to obstetric ultrasound scans if facilities and medical support are not adequate or if radiographers think that their constraints limit their ability to deal with partners.

It is suggested that more realistic guidelines for radiographers who perform obstetric ultrasonography would improve communication with patients, promote the uniform development of ultrasound services, and lift the medicolegal burden from radiographers who at present exceed their professional constraints.

We thank Drs F G M Ross and E W Williams for their helpful advice, Mrs $\mathrm{J}$ Wootton for secretarial help, and all radiographers and radiologists who replied to this survey.

\section{Reference}

1 Working party on routine ultrasound examinations in pregnancy. Report of the Royal College of Obstetricians and Gynaecologists. London: Royal College of Obstetricians and Gynaecologists,
1984.

(Accepted 4 September 1985)

\section{From the CDSC}

\section{British Paediatric Association-Communicable Disease Surveillance Centre surveillance of haemolytic uraemic syndrome 1983-4}

The haemolytic uraemic syndrome, first decribed in $1955,{ }^{1}$ is defined by the triad of microangiopathic haemolytic anaemia, thrombocytopenia, and acute nephropathy. Its severity varies, and some patients do not develop uraemia or oliguria. ${ }^{1}$ The disease principally affects children, but cases may occur in adults, often in association with pregnancy. ${ }^{2}$ The haematological and renal disorder is frequently preceded by diarrhoea, often bloody, and various pathogenic bacteria such as shigellas, especially Shigella dysenteriae serotype 1 (Shiga), ${ }^{3}$ Salmonella typhi, ${ }^{4}$ and campylobacter ${ }^{5}$ have been isolated. A recent study in Canada of 15 sporadic cases of haemolytic uraemic syndrome showed an association in 11 of them with diarrhoea caused by verotoxin producing Escherichia coli ${ }^{6}$ This cytotoxin is probably closely related to that produced by $S$ dysenteriae serotype 1 .

Surveillance of haemolytic uraemic syndrome in the British Isles began in 1983 as part of the voluntary clinical reporting scheme of the British Paediatric Association and the Communicable Disease Surveillance Centre. The results of the first two years of surveillance are reported here.

\section{Ascertainment}

In January 1983 all members of the British Paediatric Association were informed about the voluntary reporting scheme for haemolytic uraemic syndrome; diagnostic criteria and reporting forms were provided, and reminders were published in the quarterly newsletters. Microbiologists were informed through the Communicable
Disease Surveillance Centre. When a case was reported the paediatrician was asked to complete a questionnaire.

In the summer of 1983 an outbreak of haemolytic uraemic syndrome occurred in the West Midlands. Epidemiological details of these cases were obtained from a published report ${ }^{8}$ (none had been notified through the scheme though the Communicable Disease Surveillance Centre had helped in a case-control study of risk factors in the outbreak).

For the purposes of the surveillance scheme a patient with haemolytic uraemic syndrome was defined as a child under the age of 16 with acute renal failure (plasma urea concentration $\geqslant 18 \mathrm{mmol} / \mathrm{l}(108 \mathrm{mg} / 100 \mathrm{ml})$ ); microangiopathic haemolytic anaemia $(\mathrm{Hb} \leqslant 100 \mathrm{~g} / \mathrm{l}$, fragmented red cells); and thrombocytopenia (platelet concentration $\leqslant 100 \times 10^{9} / 1$ ). Patients with septicaemia, malignant hypertension, chronic uraemia, collagen, and vascular disorders were excluded.

\section{Results}

Seventy seven reports were received, 31 in 1983 and 46 in 1984, giving an annual reported incidence in the British Isles for the two years of 0.25 and 0.36 per 100000 children under 16 years. Completed questionnaires or case summaries were returned for 59 of the patients, and limited information was available from the case report forms for the remaining 18 .

The ages were given for 71 patients ( 40 girls, 31 boys) and ranged from 3 weeks to 14 years with a median of 2 years 7 months and a 